\title{
A study on the relationship between organizational structure and organizational agility: A case study of insurance firm
}

\author{
Seyed Ali Akbar Ahmadi ${ }^{a}$, Alireza Fathizadeh ${ }^{a^{*}}$, Javad Sadeghi ${ }^{b}$, Mohsen daryabeigi ${ }^{b}$ and Leili \\ Taherkhanic $^{\mathrm{c}}$
}

${ }^{a}$ Department of Public Administration, Payame Noor University, PO BOX 19395-3697, Tehran, Iran

${ }^{b} \mathrm{MSc}$ of MBA, Payam Nour University, Qeshm

${ }^{c} M S c$ of library and information, department of human arts, Takestan branch, Islamic Azad University, Takestan, Iran

\begin{tabular}{l}
\hline A R T I C L E I N F O \\
\hline Article history: \\
Received August 25, 2012 \\
Received in revised format \\
25 September 2012 \\
Accepted 4 October 2012 \\
Available online \\
October 7 2012 \\
\hline Keywords: \\
Organizational agility \\
Organizational structure \\
Complexity \\
Formalization \\
Centralization
\end{tabular}
A B S T R A C T

\begin{abstract}
The primary aim of this survey is to study the relationship between organizational structure and organizational agility in an insurance company in Iran. The statistical population includes 300 employees and managers of the proposed insurance company across in Tehran province, Iran and a sample of 73 people are selected, randomly for the survey. Questionnaire is used as a major tool of data collection. Validity of the questionnaire is confirmed through content validity by professors and experts. Reliability of the questionnaire was calculated using Cronbach alpha. SPSS software is used for data analysis. Research findings illustrate there is a significant relationship between organizational agility and two dimensions of organizational structure, i.e. formalization and centralization. No significant relationship was observed between complexity and organizational agility.
\end{abstract}

\section{Introduction}

Superiority in competition is the major purpose of any organization in the current unpredictable and changeable business environment and small shortcoming may end them up having undesirable consequences. Unpredictable, constant and unprecedented changes are dominant in the current business environment. Products and services that are universally across the organizations will not be easily accessible in future. Some organizations continue their activities with difficulty in such environment and sometimes they may be encountered with failure, because their organizational capability is not sufficient to respond environmental changes. Changes in the external environment compel organizations to react and change. Re-engineering of processes and changing of organizational structure, constitution of product development teams, implementing various programs

\footnotetext{
* Corresponding author. Tel: +989131457649

E-mail addresses: a_fathii@yahoo.com (A. Fathizadeh) 
to reinforce employees, moving towards virtual organizations and increased ability of efficient responsiveness to changes are necessary activities. Organizations must think beyond adapting with fast and unpredicted changes and utilize the potential opportunities to come up with new changes occurred in the current competition world.

Agile enterprise as the paradigm of organization in the $21^{\text {st }}$ century has many advantages since an agile unit could have a successful strategy in competitive markets with rapid changes of customers' requirements. Agility means the capability to react quickly against environmental changes. However, various researchers have represented different features for agile enterprises as well as those which are going towards this path by integrating enablers and agile capabilities. These characteristics act as directors of agility and direct manufacturing and service organizations towards more survival and competitiveness. For example, the existing literature on agility provides agility into four different classes including strategies, technologies, systems and human resources (Sherehiy et al. 2007; Yusuf et al., 1999; Batlu \& Avla 2006). Agile enterprises think beyond adapting with unexpected changes and intend to implement potential opportunities in market turbulent and achieve a stable status due to their innovations and competencies. These firms think differently about satisfying customers' requirements.

The ability to build an agile enterprise with the intended speed has not been provided, because technology development to manage the organization is still in its early stage. Thus, several important questions must be considered about agility in an agile enterprise such as what agility is and how it can be measured, etc. Responding these types of questions seems to be necessary for experts and theoreticians who design an agile enterprise.

There are different lessons from organizations, which could successfully implement organizational agility program. For instance, organizational structure is one of the most important effective factors on implementing agility programs. Relative importance of organizational structure in forming organizational processes especially organizational structure requires special care about the relationship between agility and the process of implementing organizational agility. Various studies in this field have created fast changes in replacing traditional, centralized and inactive structures with active, dynamic, participatory and self-managed organizational structures (Mihm et al., 2010).

\section{Reviewing research literature}

Research literature is represented in three sections. Agility, its concept and the existing viewpoints about it will be discussed in the first section. Literature regarding organizational structure and its dimensions are represented in the second section.

\subsection{Organizational agility}

Agility improves the organization's capability to offer high quality products and services. Therefore, it could play essential role for increasing effectiveness. Agile enterprises are always prepared to learn more, which increases profitability arising from utilizing new opportunities. Drucker is believed to be the first who proposed the term agile enterprise when he compared the structure of current manufacturing companies with a heavy ship especially after integration in terms of nature. He stated that a group of smaller ships could replace a big ship with increased flexibility and responsiveness through the nature of their structure. There are strong motivations to show agile production is the necessary condition for competitiveness. Various organizations were pressured heavily to access more flexibility, shorter delivery time and more diversity of products and services since the beginning of the 1990's. Therefore, many firms have moved to dominate challenges such as variable demand of consumers, demand for high quality and minimum cost of production as well as responding special customers' requirements. They re-engineered their businesses, renewed the structure in responding 
reacting to such challenges, and developed a modern method called organizational agility. In 1991 a group included 150 executive top managers of industry took part in a survey in which manner of competition in the American manufacturing organizations during the next 15 years was investigated. Thus "Agile Manufacturing Enterprise Forum (AMEF)" dependent on Iacocca institute was built in Lee Hay University and the term agile production was introduced (Sheridan, 1993; Strobbing, 1995; Richards, 1996; Nagel \& Dove 1991).

There is no widely accepted definition for agility since this is a new topic. Several researchers have been active in this regard since 1991 onwards and each one represented different definitions. Some of these definitions are classified in the following,

- Agility refers capability of successful production and selling of an extensive range of products with low cost, high quality, short delay times and variety of classes' size which create value for various and certain customers through production based on mass customer needs (Van Assen et al., 2001).

- It is the ability to respond effectively to events that are changed rapidly and are unexpected (Dove, 1996). Another definition specifies that agility is a comprehensive strategic response to major and significant changes, which is occurred in the dominant competitive system on trade in the economy of the first world.

- According to Yusuf et al. (1999), agile is searching competitive principles successfully in terms of speed, flexibility, creativity, being proactive, quality and profitability through integration of resources which could be re-shaped. In addition, it is the best practical technique in a specialized environment to provide services and products based on customers' requirements in a market environment where quick changes are occurred.

Agility is, in fact, a new paradigm to engineer competitive firms. The proposed paradigm indicates a step forward, which generates new meanings for better and successful performance and practically is a strategic approach to look for new conditions of business environment. Responding to different changes and looking into their advantages through strategic utilization of manufacturing, service and managerial tools and techniques are the main concepts of agility (Sharifi \& Zhang, 1999). Darvin explains in his book entitled "the origin of species" that species change during the time to be adapted with the environment and the remaining species are not stronger or more intelligent; rather they are the species, which respond changes more easily. Reflecting this theory in business helps survival of those organizations, which adapt themselves well with new and changeable environment and are ready to be changed.

Agility rejects relatively old techniques of performing things, which are suitable for static conditions of traditional operations. Creating and developing flexible firms and equipments with a very high sensitivity to environmental changes and the market are required in a competitive and very changeable environment. Agility can be described as the ability to survive and advance in a very competitive environment with continuous and unpredictable changes through fast and effective reaction towards changes as well as production of products and services based on customer's requirements (Crocitto \& Youssef, 2003). Given the fact that agility is new concept, there is no widely accepted definition (Noaker, 1994; Goldman et al., 1995; Richards, 1996; Van Assen et al., 2001), proactive reaction to changes (Goldman \& Nagel, 1993; Bessant, 2001), profitability from the environment (Noaker, 1994, Goldman \& Nagel, 1993; Goldman et al., 1995) and the ability to survive and advance with continuous and unpredicted changes (Dove, 1999; Maskell, 2001; Richards, 1996; Rigby et al. 2001).

Thus paying attention to enablers and agility capabilities play important role to create agility. Agility enablers are elements, concepts and techniques, which help obtain a desirable level of agile 
capabilities. Any organization wishes to be agile and stands in its place with confidence must have these capabilities at a desirable level. Agile capabilities have been represented in different groupings and based on diverse viewpoints. The most well-known groupings used as the primary input are responsiveness, competency, coincidence and flexibility and quickness (Lin et al., 1995; Sharifi \& Zhang 1999).

Various researchers have represented different characteristics for agile enterprises to move towards agility by combining enablers and agility capabilities. These characteristics act as directors of agility and direct manufacturing and service organizations towards more survival and competitiveness. For instance, the existing literature regarding agility based on nature and scope divides tools, which provide agility into four various classes including strategies, technologies, systems and human resources (Sherehiy et al., 2007; Yusuf et al., 1999; Batlu \& Avla, 2006). In addition, the existing literature about each group is divided into different subgroups that the purpose is a more clear representation and highlighting some key factors of agility in each group and subgroup. Agility must be in all functional areas of the organization to respond changeable needs effectively. Therefore, obtaining agility requires flexibility and sensitivity in strategies, technologies, systems and human resources (Bierd et al., 2001, Bharadwaj, 2000; Yusuf et al., 1999).

\subsubsection{Dimensions of agility}

Firms are complex phenomena, which should be observed systematically and agility is a complex concept too that four dimensions have been suggested to achieve it. These dimensions could be observed systematically in the following diagram and it is possible to define an agile firm.

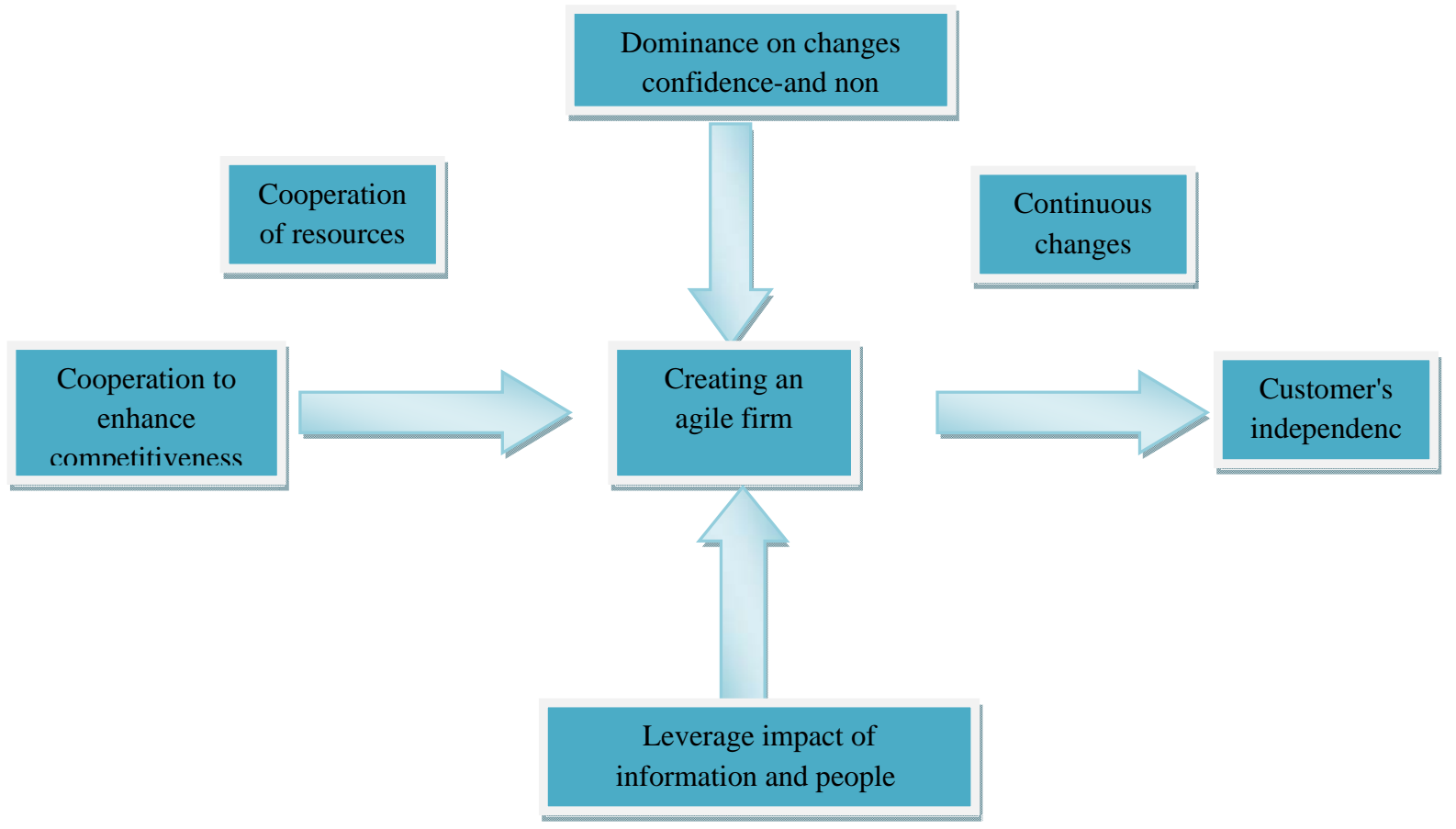

Organizations moved in the path to dominate challenges such as changeable demand of consumers, demand for high quality and minimum cost of production as well as responsiveness to special needs of customers for survival and advancement. They re-engineered their businesses and renewed their structure in responding to these challenges and developed a modern approach called organizational agility (Sheridan, 1993; Strobbing, 1995; Richards, 1996; Nagel \& Dove, 1991).

Agility rejects relatively old methods of doing things, which are suitable for static conditions of traditional operations. Creating and developing too flexible organizations and equipments with a very 
high sensitivity to environmental changes and the market are required in a competitive and very changeable environment. Agility has been defined as the ability to survive and advance in a very competitive environment with continuous and unpredictable changes through quick and effective reaction towards changes as well as production of products and services based on customer's need (Crocitto \& Youssef, 2003).

\subsubsection{Characteristics of organizational agility}

Organizational agility means the ability for survival and advancement in an environment with continuous and unpredictable changes. Indeed, agility is a response to challenges of enjoying quick and continuous changes of global markets for high quality, excellent performance and customized products and services. Agile enterprises not only continue their survival in such environments but also obtain numerous benefits from this changeable and uncertain environment and create golden opportunities for themselves. In order to achieve agility an organization should:

- Evaluate performance of its personnel and value of its products and services continuously.

- Respond permanent changes in needs of its customers.

- Learn new things.

- Has high information content.

- Be ready to respond sudden changes and events.

- Use advanced technologies.

- Use new opportunities, which enhance profitability and productivity.

\subsection{Organizational structure}

Implementing each organizational process needs paying attention to its necessities and a suitable context based on organization studies. Organizational structure is one of the most important dimensions of each organization. It can be stated as the most major part of the organization after organizational purposes. Structure is compared to skeleton and formation basis of other internal sectors and external environment of the firm (Powell, 2002). Organizational structure is one of the most important concepts in constitution of an organization. Extensiveness of definitions and effectiveness of structure focus on its importance especially there is a relationship among any organizational change and dimensions of the organization's structure.

Various definitions have been represented for organizational structure where each one refers one functional aspect of structure. Some people view structure as a device to divide labor in the organization, which could determine individuals' status in organizational diagram. On the other hand, some other people believe structure provides suitable conditions to control things in the organization. Organizational structure is the model and map of relationships and interactions among sections and elements of an organization (Cyert \& March, 2007). Formal relationships among individuals, status of jobs and organizational posts, access level to information framework, job descriptions (how to do works), how to allocate resources, rules and regulations, mechanisms to follow and execute rules and coordination among activities are some of the consequences of creating and designing organizational structure (Ergenli et al., 2007).

Organizations have various types of structure used in terms of requirement and conditions of that organization. In a general, classification structure of organizations is divided into two types: mechanical structure and organic structure. Mechanical structure is usable for stable and predictable environments and organic structure is used in turbulent and changeable environments (Gresov \& Drazin, 2007). 
Mechanical structure of the organization is recognized by characteristics such as high complexity and formalization, centralization and planned behaviors in the framework of rules. In this structure, the manager depends on policies of the firm and acts slowly in reacting towards unpredictable events (Mihm et al., 2010). On the other side, organic structure is flexible and degrees of individuals' effects are based on skill and knowledge. Tasks in this structure are flexible and information exchange is emphasized. Decentralized authorizations, fewer rules and regulations, informal communication network and considering self-control provide conditions for the organic structure to adapt more with the environment (March \& Simon, 2009).

Powell (2002) explained that organic structures provide suitable conditions to implement organizational agility programs. In fact, there are different characteristics such as flexibility, dynamism, mobility, freedom of action and paying attention to proficiency and competency. Difference in various organizational structures is associated with differences in their dimensions and components. Studying all aspects of structure is too time-consuming because of extensiveness and variety in structure studies (it is more due to antiquity of this concept). Thus, Robbins' research about structure dimensions (three components of complexity, formalization and centralization) is the standard to study organizational structure in this survey due to its high antiquity and scientific support (Robbins, 1998).

A) Complexity: it refers the limit that there is separation in the organization (Child, 2008). Daft believes complexity is number of management levels in the organization (Daft, 1998: 213). Generally complexity is applied to amount of job titles (dispersion of jobs in the organization), number of managerial hierarchy and levels, education level and geographical dispersion of units in the organization from each other. Complexity includes vertical, horizontal and geographical complexities (Gresov \& Drazin, 2007). Geographical complexity considers separation among the units based on geographical situation. Vertical complexity refers levels of the organization and managerial layers and horizontal complexity refers separation and number of jobs of the same group and rank at one organizational level (March \& Simon, 2009).

B) Formalization: it refers the degree that organizational jobs have become standardized (Robbins, 1998). Generally, it is said to the degree that rules, regulations, instructions, by-laws and job descriptions of personnel in the organization are compiled and written (Gresov \& Drazin, 2007).

C) Centralization: the third index of organizational structure is centralization. Most theoreticians agree it refers the degree a decision-making (financial, human force, plan and exceptional cases of the organization) are centralized in an organization and secondary activities of decision-making are affected (Child, 2008). Centralization considers independence level of a job in decision-making and selection. Some decision-making subsets that could form a centralized scope include determining the programs, resource allocation, attraction of resources, giving reward, employment and firing, performance assessment, enhancement, regulation and budget allocation, having access to information and controlling the processes (Mihm et al., 2010).

\section{Research hypotheses}

There is a significant relationship between organizational agility and organizational structure in Alborz Insurance Company.

\subsection{Secondary hypotheses}

1- There is a significant relationship between organizational agility and complexity in Alborz Insurance Company. 
2- There is a significant relationship between organizational agility and formalization in Alborz Insurance Company.

3- There is a significant relationship between organizational agility and centralization in Alborz Insurance Company.

\section{Conceptual model of the survey}

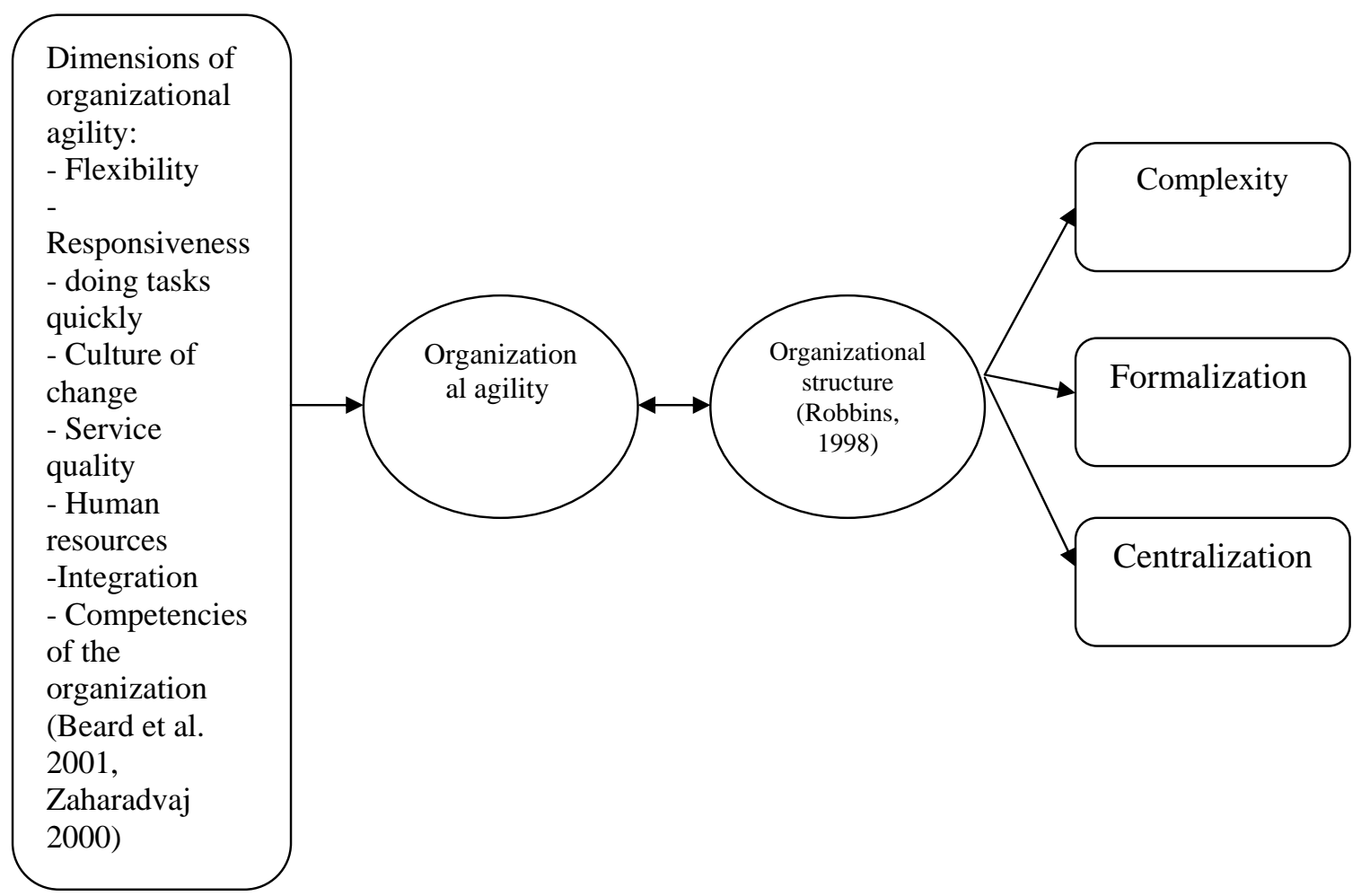

Fig. 2. Conceptual model

\section{Research methodology}

This survey was conducted using descriptive-correlation method. It's descriptive because it studies the existing status in the organization and is correlation because it studies the relationship among research variables. Statistical population included employees of Alborz Insurance Company in Tehran province, which was equal to 300 people. Therefore we could use the following formula to calculate the minimum number of sample size,

$n=\frac{N \times z_{\alpha / 2}^{2} \times p \times q}{\varepsilon^{2} \times(N-1)+z_{\alpha / 2}^{2} \times p \times q}$,

where $N$ is the population size, $p=1-q$ represents the yes/no categories, $z_{\alpha / 2}$ is CDF of normal distribution and finally $\varepsilon$ is the error term. Since we have $p=0.5, z_{\alpha / 2}=1.96$ and $N=300$, the number of sample size is calculated as $n=73$.

Organizational agility and organizational structure questionnaires were used to collect data. Validity of the questionnaires was confirmed through content validity and experts' views. Cronbach alpha was used to measure reliability of the questionnaires that Cronbach alpha related to organizational 
structure was equal to 0.874 and that of organizational agility was equal to 0.819 , which indicated reliability of questionnaires.

Table 1

Structure of the questionnaires

\begin{tabular}{cllc}
\hline Row & \multicolumn{1}{c}{ Variable } & Dimension & Questions \\
\hline 1 & & Flexibility & $1-3$ \\
2 & & Responsiveness & $4-6$ \\
3 & & Culture of change & $7-11$ \\
4 & Organizational agility & Speed & $12-14$ \\
5 & & Integration & $15-16$ \\
\hline 6 & & Service quality & $20-22$ \\
7 & & Competencies of the organization & $20-22$ \\
\hline 8 & & Human resources & $23-27$ \\
\hline 9 & & Complexity & $1-5$ \\
10 & & Formalization & $6-10$ \\
11 & Organizational structure & Centralization & $11-15$ \\
\hline
\end{tabular}

Descriptive statistics which study demographic variables such as gender, education level, etc. are studied to analyze the collected data. Kolmogoroff-Smirnoff test was used in analytical statistics to study data normality. After determining data normality, Pierson correlation test was used to study relations among organizational agility and organizational structure. Mean and standard deviation were applied to study dimensions of organizational agility and organizational structure in Alborz Insurance Company. Analyses were conducted using SPSS software.

\section{Results of statistical analysis}

Kolmogoroff-Smirnoff test has been used to determine whether data is normal or not and the results are displayed in the table (2). Results indicate normality of data related to research variables.

$\mathrm{H}_{0}$ : data is normal (data is obtained from normal population).

$\mathrm{H}_{1}$ : data is not normal (data is not obtained from normal population).

If significance level is more than the error amount, $\mathrm{H}_{0}$ is concluded and if it is less than error amount, $\mathrm{H}_{1}$ is concluded.

Table 2

Results of statistical analysis

\begin{tabular}{lcccc}
\hline Variable & $\begin{array}{c}\text { Significance } \\
\text { level }\end{array}$ & Error amount & $\begin{array}{c}\text { Confirming the } \\
\text { hypothesis }\end{array}$ & Conclusion \\
\hline Flexibility & 0.550 & 0.05 & $\mathrm{H}_{0}$ & It is normal \\
Responsiveness & 0.532 & 0.05 & $\mathrm{H}_{0}$ & It is normal \\
Culture of change & 0.367 & 0.05 & $\mathrm{H}_{0}$ & It is normal \\
Speed & 0.189 & 0.05 & $\mathrm{H}_{0}$ & It is normal \\
Integration & 0.067 & 0.05 & $\mathrm{H}_{0}$ & It is normal \\
Service quality & 0.109 & 0.05 & $\mathrm{H}_{0}$ & It is normal \\
Competencies of the organization & 0.201 & 0.05 & $\mathrm{H}_{0}$ & It is normal \\
Human resources & 0.111 & 0.05 & $\mathrm{H}_{0}$ & It is normal \\
Complexity & 0.101 & 0.05 & $\mathrm{H}_{0}$ & It is normal \\
Formalization & 0.089 & 0.05 & $\mathrm{H}_{0}$ & It is normal \\
Centralization & 0.452 & 0.05 & $\mathrm{H}_{0}$ & It is normal \\
Organizational agility & 0.099 & 0.05 & $\mathrm{H}_{0}$ & It is normal \\
Organizational structure & 0.211 & 0.05 & $\mathrm{H}_{0}$ & It is normal \\
\hline
\end{tabular}


Based on the information of Table 2, we can conclude that all collected data is normal. Mean, standard deviation and dispersion coefficient were used to study the status of organizational agility variables in Alborz Insurance Company.

Table 3

Status of organizational agility variables in Alborz Insurance Company

\begin{tabular}{lccc}
\hline \multicolumn{1}{c}{ Index } & Mean & Standard deviation & Dispersion coefficient \\
\hline Flexibility & 3.06 & 0.82 & 0.27 \\
Responsiveness & 3.18 & 0.84 & 0.30 \\
Culture of change & 2.70 & 0.92 & 0.34 \\
Speed & 3.35 & 0.79 & 0.33 \\
Integration & 3.50 & 0.86 & 0.34 \\
Service quality & 3.18 & 0.65 & 0.30 \\
Competencies of the organization & 2.90 & 0.77 & 0.27 \\
Human resources & 2.88 & 0.68 & 0.24 \\
Organizational agility & 3.19 & 0.75 & 0.37 \\
\hline
\end{tabular}

According to obtained findings in the Table 3 it could be claimed that the existing status of Alborz Insurance Company is at average level in the scope of organizational agility and its amount is equal to 3.19. Integration of the organization with mean equal to 3.50 has the best status and culture of change with mean 2.70 is the worst index among organizational agility variables. According to the obtained findings from mean, standard deviation and dispersion coefficient indexes related to organizational structure variables it was determined that status of organizational structure in Alborz Insurance Company was at an average level with mean amount of 3.28.

\section{Table 4}

Findings from mean, standard deviation and dispersion

\begin{tabular}{clccc}
\hline Row & \multicolumn{1}{c}{ Dimensions } & Mean & standard deviation & dispersion coefficient \\
\hline 1 & Complexity & 3.25 & 0.66 & 0.23 \\
2 & Formalization & 3.13 & 0.75 & 0.31 \\
3 & Centralization & 3.44 & 0.68 & 0.27 \\
4 & Organizational structure & 3.28 & 0.63 & 0.26 \\
\hline
\end{tabular}

\subsection{Testing research hypotheses}

Testing secondary hypothesis 1: There is a significant relationship between organizational agility and complexity in Alborz Insurance Company.

$\mathbf{H}_{\mathbf{0}}: \boldsymbol{\rho}=\mathbf{0}$ There is no relationship between organizational agility and complexity in Alborz Insurance company.

$\mathbf{H}_{\mathbf{0}}: \quad \boldsymbol{\rho} \neq \mathbf{0} \quad$ There is a relationship between organizational agility and complexity in Alborz Insurance company.

Table 5

Testing research hypothesis 1

\begin{tabular}{ccc}
\hline Variable & Significance level & Correlation coefficient \\
\hline $\begin{array}{c}\text { Relationship between organizational agility and } \\
\text { complexity }\end{array}$ & 0.291 & -0.111 \\
\hline
\end{tabular}

Amount of significance level was obtained equal to 0.291 and more than error amount of 0.05 by conducting the test. Therefore, $\mathrm{H}_{0}$ is confirmed, it means that no significant relationship is observed between organizational agility and complexity in Alborz Insurance Company. As a result, secondary hypothesis 1 is rejected. 
Testing secondary hypothesis 2: there is a significant relationship between organizational agility and formalization in Alborz Insurance Company.

$\mathbf{H}_{\mathbf{0}}: \boldsymbol{\rho}=\mathbf{0}$ There is no relationship between organizational agility and formalization in Alborz Insurance company.

$\mathbf{H}_{\mathbf{0}}: \quad \boldsymbol{\rho} \neq \mathbf{0}$ There is a relationship between organizational agility and formalization in Alborz Insurance company.

\section{Table 6}

Testing research hypothesis 2

\begin{tabular}{ccc}
\hline Variable & Significance level & Correlation coefficient \\
\hline Relationship between organizational agility and formalization & 0.001 & -0.348 \\
\hline
\end{tabular}

Amount of significance level was obtained equal to 0.001 at confidence level $99 \%$ by conducting the test. Therefore, $\mathrm{H}_{0}$ is rejected; it means that there is a significant relationship between organizational agility and organizational structure in terms of formalization dimension in Alborz Insurance Company. As a result, secondary hypothesis 2 is confirmed. Amount of correlation coefficient was obtained equal to -0.348 .

Testing secondary hypothesis 3: There is a significant relationship between organizational agility and centralization in Alborz Insurance Company.

$\mathrm{H}_{\mathbf{0}}: \rho=\mathbf{0}$

There is no relationship between organizational agility and centralization in Alborz Insurance Company.

$\mathrm{H}_{0}: \rho \neq 0$

There is a relationship between organizational agility and centralization in Alborz Insurance Company.

Table 7

Testing research hypothesis 3

\begin{tabular}{ccc}
\hline Variable & Significance level & Correlation coefficient \\
\hline Relationship between organizational agility and centralization & 0.011 & -0.264 \\
\hline
\end{tabular}

Amount of significance level was obtained equal to 0.011 by conducting the test. Therefore, $\mathrm{H}_{1}$ is confirmed, which means that there is a significant relationship between organizational agility and organizational structure in terms of centralization dimension in Alborz Insurance Company. As a result, secondary hypothesis 3 is confirmed. Correlation coefficient between the two variables is equal to -0.264 that shows indirect relationship between these two variables.

Testing primary hypothesis: there is a significant relationship between organizational agility and organizational structure in Alborz Insurance Company.

$\mathrm{H}_{0}: \rho=0$

There is no relationship between organizational agility and organizational structure in Alborz Insurance Company.

$\mathbf{H}_{0}: \rho \neq 0$

There is a relationship between organizational agility and organizational structure in Alborz Insurance Company.

Table 8

Testing research hypothesis

\begin{tabular}{ccc}
\hline Variable & Significance level & Correlation coefficient \\
\hline $\begin{array}{c}\text { Relationship between organizational agility and organizational } \\
\text { structure }\end{array}$ & 0.001 & 0.349 \\
\hline
\end{tabular}


Amount of significance level was obtained equal to 0.001 at confidence level $99 \%$ by conducting the test. Therefore, $\mathrm{H}_{0}$ is rejected; it means that there is a significant relationship between organizational agility and organizational structure in Alborz Insurance Company. As a result primary hypothesis is confirmed. Amount of correlation coefficient is equal to 0.349 .

\section{Recommendations}

In order to improve organizational agility in Alborz Insurance Company the following recommendations are represented.

Structure of the organization: structure of the organization must be flexible. The following acts could be done regarding the organization's scope:

- Partnership with other organizations and even among various branches of Alborz Insurance

- Improving flexibility through decentralization and adopting flexible structures

- Propagation of culture of change and modernity

Individuals: ability and flexibility of human play an important role in an agile enterprise that is faced with continuous environmental changes. The following acts are effective in this regard:

- Focusing on group activities and participation culture

- Granting authority to the personnel in the organization

- Relying on education as an important tool

- Training various skills to the personnel

Technology to respond changes and offer appropriate services: an agile production system has the capability to confront unpredicted changes. These changes could be in products' model. Thus, an agile production system must have the capability to produce new products. The following actions are important in this regard:

- Investment in appropriate and modern hardware technologies

- Using flexible systems of service offering to adapt with changes in composition and manner of ordering the insurance policies

- Utilizing flexible service support systems to adapt with changeable conditions to order policy insurances

- Establishment of a system to issue electronic insurance

Information technology to accelerate responsiveness and doing tasks quickly: one of the distinctions among agile systems and other systems is high information content. Moreover, volume of the exchanged information among partner companies is high and this makes the necessity of protecting key information in each organization more obvious. Therefore, agile enterprises need advanced and flexible information and communication systems to assure fluent and secure flow of information given to the problems and adapt themselves with changing conditions. The following acts are recommended in this regard:

- Using appropriate standards and protocols in information exchange among the organizations

- Using modern information and communication systems and technology in order to make appropriate and timely relation among partner companies

- Integration of dispersed elements including customers, suppliers and colleagues in virtual organizations 


\section{References}

Bessant, J., Kowles, D., Franci, D., \& Meredith, S. (2001). Developing the agile enterprise; agile manufacturing: The 21st century competitive strategy. Elsevier Science, 113-130.

Bharadwaj, A.S. (2000). A resource-based perspective on information technology capability and firm performance: An empirical investigation. MIS Quarterly, 24(1), 169-196.

Child, J. (2008). Organization structure, environment, and performance: the role of strategic choice. Sociology, 6, 1-22

Crocitto. M., \& Youssef. M. (2003). The human side of organizational agility. Industrial Management \& Data Systems, 103(6), 388-397,

Daft, R. L, (1998). Organization theory and design. $3^{\text {rd }}$ ed., West publishing company.

Dove, R. (1996). Agile and Otherwise. Paroduction Magazine.

Ergenli, A., Saglam, G., \& Metin, S. (2007). Psychological empowerment and its relationship to trust in immediate managers. Journal of Business Research, 60, 41-49.

Goldman, S.L., Nagel, R.N., \& Preiss, K. (1995). Agile Competitors and Virtual Organizations: Strategies for Enriching the Customer. Van Nostrand Reinhold, New York, NY.

Gresov, C., \& Drazin, R. (2007). Equifinality: functional equivalence in organization design. Academy of Management Review, 22, 403-428

Hwang, C. L., \& Yoon, K. (1981). Multiple Attribute Decision Making: Methods and Applications. Springer-Verlag: New York.

Iacocca Institute (1991). 21st Century Manufacturing Enterprise Strategy, Vol. 1, Lehigh University, Bethlehem, PA.

Iacocca Institute (1991). 21st Century Manufacturing Enterprise Strategy, Vol. 2, Lehigh University, Bethlehem, PA.

Jafarnejad, A., Shahaee, B. (2008). An introduction on organizational agility and agile production. Institute of Mehraban Ketab Publications

Lai, K.H., \& Cheng, T.C.E. (2003). Initiatives and outcomes of quality management implementation across industries. Omega, 31(2), 141-54.

March, J., \& Simon, H. (2009). Organizations. Blackwell, Cambridge, MA, PP 195-324

Maskell, B. (2001). The Age of Agile Manufacturing. Supply Chain management: An International Journal, 6(1), 5-11.

Mihm, J., Loch, C. H., Wilkinson, D., \& Huberman, B. A. (2010). Hierarchical structure and search in complex organizations. Management science, 56(5), 831-848.

Mintzberg, H. (1979). The structuring of organization. Englewood cliff, NJ, prentice hall.

Noaker, P. M. (1994). The Search for Agile Manufacturing. Manufacturing Engineering, 40-43.

Richards, C. (1996). Agile Manufacturing: Beyond Lean?. Production and Inventory Management Journal, 2, 60-64.

Rigby, C., Day, M., Forrester, P., \& Burnett, J. (2001). Agile supply: Rethinking systems, systems thinking, systems practice. International Journal of Agile Management Systems, 2/3, 178-186.

Robbins, S. P. (1998). Organization Theory. New York, Prentice hall.

Sharifi. H., \& Zhang, Z. (1999). A methodology for achieving agility in manufacturing organizations: an introduction. International Journal of Production Economics, 62 (1-2), 7-22.

Sherehiy, B., Karwowski, W., \& Layer, J. K. (2007). A review of enterprise agility: Concepts, frameworks, and attributes. International Journal of Industrial Ergonomics, 37, 445-460.

Siggelkow, N \& Rivkin. J. W. (2007). Speed and search: designing organizations for turbulence and complexity. Organizational Science, 16, 101-122.

Van Assen, M. F., Hans, E. W., \& Van De Velde, (2001). An agile planning and control framework for customer-order driven discrete parts manufacturing environments. International Journal of Agile management Systems, 2/1, 16-23

Yusuf, Y. Y., Sarhadi, M., \& Gunasekaran, A. (1999). Agile manufacturing: the drivers, concepts and attributes. International Journal of Production Economics, 62 (1), 33-43. 